\title{
Bubbling test to recognize retrograde air escape via the nasolacrimal system during positive airway pressure therapy
}

\section{Bachour, Adel}

2017-01

Bachour , A , Maasilta , P , Wares , J \& Uusitalo , M 2017 , ' Bubbling test to recognize retrograde air escape via the nasolacrimal system during positive airway pressure therapy ', Sleep Medicine , vol. 29 , pp. 35-36 . https://doi.org/10.1016/j.sleep.2016.08.026

http://hdl.handle.net/10138/233880

https://doi.org/10.1016/j.sleep.2016.08.026

publishedVersion

Downloaded from Helda, University of Helsinki institutional repository.

This is an electronic reprint of the original article.

This reprint may differ from the original in pagination and typographic detail.

Please cite the original version. 
Video-Clinical Corners

\title{
Bubbling test to recognize retrograde air escape via the nasolacrimal system during positive airway pressure therapy
}

\author{
Adel Bachour ${ }^{\text {a, }}{ }^{*}$, Paula Maasilta ${ }^{\text {a }}$, Juho Wares ${ }^{\mathrm{b}}$, Marita Uusitalo ${ }^{\mathrm{c}}$ \\ ${ }^{a}$ University of Helsinki, Heart and Lung Centre, Sleep Unit, Finland \\ ${ }^{\mathrm{b}}$ University of Helsinki, Skin and Allergy Hospital, Allergy Department, Finland

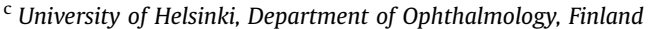

\section{A R T I C L E I N F O}

\section{Article history:}

Received 9 April 2016

Received in revised form

27 August 2016

Accepted 28 August 2016

Available online 5 November 2016

\section{Keywords:}

CPAP therapy

Side effect

Air leak

Eye

Lacrimal canal

\section{Introduction}

Reports have identified dry eyes, epiphora and superficial punctate keratitis as side effects of CPAP therapy [1,2]. These symptoms have been attributed to direct air leak towards the eyes due to poor mask fit.

However, in 2004, Singh et al. [3] reported CPAP-associated retrograde air escape via the nasolacrimal system (CRANS), causing dry eyes, epiphora and eyelid fluttering.

This is a report of a video describing a bubbling test for the diagnosis of CRANS.

\section{Case description}

A 66-year-old man with no history of nasolacrimal surgery used CPAP therapy $\left(15 \mathrm{~cm} \mathrm{H}_{2} \mathrm{O}\right.$ ) daily (mean $7 \mathrm{~h} 58 \mathrm{~min}$ ) for 20 years. Last year (2014), the patient complained of discomfort in both eyes, waking him up several times during the night. The patient's eyes were red, his eyelids were swollen, his daily CPAP decreased by

\footnotetext{
* Corresponding author. Helsinki University Hospital, Sleep Unit, PO Box 160 00029 HUS, Finland.

E-mail addresses: adel.bachour@hus.fi, adel.bachour@gmail.com (A. Bachour).
}

$35 \mathrm{~min}$, the mean leak was $2.4 \mathrm{~L} / \mathrm{min}$, he had residual apnea, and his hypopnea index was $1.3 / \mathrm{h}$.

The CPAP device (Autoset S7) was upgraded to a model that indicates more therapy details (Autoset S9), and his nasal mask (ResMed, Mirage Activa LT) was replaced with another nasal mask (ResMed Softgel) that had a firmer cushion. The patient felt slight amelioration of his eye symptoms.

\subsection{Bubbling test}

A few drops of physiological saline (B. Braun Melsungen AG, Germany) were applied to the patient's eyes while he was in a supine position and awake. After starting the CPAP device, an air leak was noticed, emerging as bubbles from the lower lacrimal punctum in both lower eyelids (video 1 ). This bubbling confirmed the diagnosis of CRANS.

Supplementary data related to this article can be found online at http://dx.doi.org/10.1016/j.sleep.2016.08.026.

The use of a CPAP oral mask could reduce nasal pressure by pushing the soft palate backward, thereby reducing CRANS. Bubbling was absent with the oral mask (Oracle ${ }^{\mathrm{TM}}$ Oral Mask HC452, Fisher \& Payke Healthcare, New Zealand), but unfortunately the mask induced nausea and proved to be intolerable.

Dissolvable lacrimal plugs (Herrick Lacrimal Plugs, Lacrimedics Inc., Eastsound, WA, USA) were inserted into both inferior lacrimal canaliculi (size $0.4 \mathrm{~mm}$ to the right and $0.5 \mathrm{~mm}$ to the left eye). The patient felt substantial improvement with his eye symptoms and signs. Thereafter, permanent silicone lacrimal plugs (UltraPlug, Angiotech, Surgical Specialities Corporation, Reading, PA, USA) were inserted into both lower lacrimal puncta (size $0.4 \mathrm{~mm}$ to the right and $0.5 \mathrm{~mm}$ to the left side). Six months after insertion of the lacrimal plugs, the patient was followed up and it was found that he remained symptom free. The patient continued his daily CPAP use at his initial level ( $7 \mathrm{~h}$ and $56 \mathrm{~min}$ ); the mean leak was $1.2 \mathrm{~L} / \mathrm{min}$, the 95th leak was $54 \mathrm{~L} / \mathrm{min}$, and the residual AHI was $1.4 / \mathrm{h}$.

\section{Video 1}

A few drops of physiological saline were applied to the patient's eyes while he was in a supine position and awake. After starting the 
CPAP device, an air leak was noticed, emerging as bubbles from the lower lacrimal punctum in both lower eyelids, thereby confirming the leak (CRANS). The bubbling was more noticeable when the lower eyelid was pulled slightly downwards. Within seconds of CRANS, the eye became red and the eyelid began to flutter.

\section{Discussion}

This video demonstrated a bubbling test to confirm a diagnosis of retrograde air escape via the nasolacrimal system during CPAP therapy (CRANS). The patient had no previous lacrimal surgery, and CRANS was treated successfully with lacrimal plugs.

CRANS may be underdiagnosed and classified as a mask leak. However, in any CPAP-related eye symptom, CRANS should not be excluded; failing to do so may cause therapy to fail. Suspected CRANS should warrant polysomnography, in order to exclude mask-related air leaks [3]. A mask-fit test can reveal mask air leaks, whereas the bubbling test indicates CRANS. Moreover, the coexistence of a mask-related leak does not exclude CRANS. It was recently demonstrated that more than half of the CPAP patients at the present institution experienced continuously disturbing leaks and that this disturbance did not correlate with the size of the measured leak [4]. A substantial leak may effectively go unnoticed by the patient. Alternatively, a small leak blowing on a sensitive area, such as the eye, may disturb the patient considerably [4]. It was previously shown that $30 \%$ of mask switching was due to a leak and that only half of patients benefited from switching masks, suggesting that the possibility of CRANS is substantial [5].

The majority (70\%) of tears flow through the lower canaliculi and 30\% through the upper canaliculi. Lacrimal plugs were inserted into the lower punctum, where the bubbling was observed.
In conclusion, it is proposed that the bubbling test be used to confirm CPAP-associated retrograde air escape via the nasolacrimal system (CRANS). The intrusion of silicone lacrimal plugs prevented the leak.

\section{Funding}

The Helsinki University Special Fund provided financial support in the form of research grant funding (Y2016SK002).

\section{Conflict of interest}

None.

The ICMJE Uniform Disclosure Form for Potential Conflicts of Interest associated with this article can be viewed by clicking on the following link: http://dx.doi.org/10.1016/j.sleep.2016.08.026.

\section{References}

[1] Harrison W, Pence N, Kovacich S. Anterior segment complications secondary to continuous positive airway pressure machine treatment in patients with obstructive sleep apnea. Optometry (St Louis, Mo.) 2007;78:352-5.

[2] Stauffer J, Fayter N, MacLurg B. Conjunctivitis from nasal CPAP apparatus. Chest 1984;86:802.

[3] Singh NP, Walker RJ, Cowan F, et al. Retrograde air escape via the nasolacrimal system: a previously unrecognized complication of continuous positive airway pressure in the management of obstructive sleep apnea. Ann Otol Rhinol Laryngol 2014;123:321-4.

[4] Bachour A, Vitikainen P, Virkkula P, et al. CPAP interface: satisfaction and side effects. Sleep Breath 2013;17:667-72. http://dx.doi.org/10.1007/s11325-0120740-0.

[5] Bachour A, Vitikainen P, Maasilta P. Rates of initial acceptance of PAP masks and outcomes of mask switching. Sleep Breath 2015. http://dx.doi.org/10.1007/ s11325-015-1292-x. 